\title{
Under the Radar: The Role of Invisible Discourse in Understanding Class-Based Privilege
}

\author{
Melissa R. Sanders* and Ramaswami Mahalingam \\ University of Michigan
}

Group-based privileges are supported and reproduced in part by control of discourse about identity and structural inequality. In the case of social class, this discourse is largely absent. This article explores the ways in which the lack of explicit and sanctioned discourse on social class affirms and reproduces class privileges. Qualitative thematic content analysis was used to analyze the final papers of students $(N=82)$ who participated in a semester long class-focused intergroup dialogue course. Content analysis found that students came into the dialogues with low levels of class salience. The dialogue course was an informative and fulfilling experience for most students, but the majority of students still had difficulty discussing class based privileges. This difficulty in engaging in an open and disruptive form of class discourse was in part due to the tendency to conflate discussions of class with race, taboos against discussing social class, and the presence of negative stereotypes about class groupings.

Privileges, broadly speaking, are the unearned benefits accorded to those with dominant group membership (Cole, 2009; Mahalingam \& Leu, 2005). Much research has articulated and explored how privilege manifests along certain lines of identity (see Pinterits, Poteat, \& Spanierman, 2009, for a review). Although this work is very important, the social mechanisms which support and reproduce these forms of privilege receive less direct attention. In this article, we suggest that control of discourse around a social identity functions as a way to normalize privilege and reduce conflict around structural inequalities. This can occur either as a dominant form of discourse, such as explicit socialization as regarding gender, or alternately can occur as an absence of discourse. We propose that within an American context privileges rooted in social class are upheld by a lack of clear

\footnotetext{
* Correspondence concerning this article should be addressed to Melissa R. Sanders, Department of Psychology, University of Michigan, Ann Arbor, MI 48105 [e-mail: mrsander@umich.edu] the data.

We express our thanks to Kate Billerbeck and Kimberly Kuhlman for their help with the coding
} 
and explicit discourse. This lack of discourse-manifested as taboos restricting discussions of money or economic status - prevents economically advantaged individuals from critically reflecting on their privileges, rendering those privileges invisible, and further renders economically disadvantaged individuals mute and unable to discuss their lived experiences.

This article examines how the lack of discourse on social class relates to individuals' awareness of their own class-based privileges. It should be noted that this work illustrates the peculiarities of class in an American context and may not be generalizable to other cultural contexts. In the following sections, we review the previous research on social class and theories of discourse with a particular focus on how these concepts manifest in higher educational settings. Then, we present the results of the qualitative analyses of a set of final papers of students who engaged in semester-long intergroup dialogues on social class followed by a discussion on the relevance of these findings to the study of privilege and social class.

\section{Approaches to Social Class}

Arguably, The Communist Manifesto (Marx \& Engels, 1962) has been the most pervasive and influential work regarding the theoretical construction of social class. Marx and Engel's positioning of individuals according to their relation to the means of production has been adopted and implemented by sociologists (Kamieniecki \& O'Brien, 1984). Three visible markers of class-income, occupational prestige, and educational attainment - are often used as objective markers of an individual's class position. They are widely considered to be face valid, because each of them have an intuitive and direct link to one's economic conditions or sites of employment (Schooler \& Schoenbach, 1994). These markers are some of the easiest and clearest ways to measure social class, which makes them particularly useful for social scientists studying class (Kamieniecki \& O'Brien, 1984).

There is no doubt that objective markers of social class are useful and informative. However, it is important to consider carefully what aspect of class privilege is measured by these markers. Objective markers alone are useful to impose social categories on different populations, but these categorizations are assigned by the researchers and may not reflect the categorized individuals' own understanding of social class. For studies seeking to compare the direct impact of tangible material conditions on certain phenomena this approach is appropriate. On the other hand, for studies in which these objective markers act as a proxy for individuals' classbased identity, values, or expectations, reliance solely on objective markers may be problematic.

Social class is an axis along which we identify others and are ourselves identified in turn (Argyle, 1994; Gordon, 1951; Surridge, 2007), a fact which is sometimes ignored by those taking a strictly objective approach to social class. 
Explorations of the subjective identity-based aspects of social class, however, are extremely relevant to the field of psychology. Typically, quantitative studies find that class identity is congruent with objective markers of social class. Those with working class identities, for example, have been found to have the levels of income, occupational prestige, and educational attainment typical of those objectively placed in the working class (Surridge, 2007; Sims, 1951). Qualitative research, however, suggests that one's class identity is not always congruent with one's material conditions. Bullock and Limbert (2003) found that one-third of low-income women enrolled in an educational training program identified as lower middle class or higher despite their objective class positions. Similarly, Jones (2003) found that professors from low-income backgrounds retained the class identities forged in their childhood, often actively rejecting the upper middle class status their career and income afforded them.

\section{Habitus and Discourse}

The two approaches to class described above, objective conditions and subjective class-based identity, may reflect an individual's privileged or marginalized position, but do not give insight into how social class identity develops. Specifically, the process by which material conditions are internalized and abstracted into social identities which impact how we approach the world and what expectations we hold is unclear. Bourdieu's (1977) concept of habitus provides particularly useful insight into this process. Broadly understood, habitus is the aggregated and largely unspoken values, norms, expectations, and privileges that are derived from a particular set of material conditions. Bourdieu (1977) argues that class-based differential access to resources and opportunities leads to externally produced necessities, which in turn cause members of a particular class to behave in certain ways, make certain interpretations about their place in society and the way the world functions, and adjust their expectations of their future opportunities accordingly. The flexible worldview that develops as a result of these externally imposed limitations, then, becomes a lens which guides individuals' behaviors and the resulting behaviors serve as socialization for their children which reproduces and strengthens the habitus.

Bourdieu (1977) also emphasizes the role that discourse (or, more specifically, the lack of discourse) plays in the perpetuation and reproduction of habitus. Habitus functions as an invisible framework, the impact of which leads us to believe that certain aspects of life are self-evident, can be taken for granted, and need no discussion. The habitus-reproducing lines of discourse develop out of the dominant group; the dominant form of discourse is therefore one which naturalizes and legitimizes the position of the most privileged (and therefore most structurally powerful) group in society. Discourse determines not only what is acceptable to speak about, but also how it can be spoken of and who can speak. A lack of 
discourse for the dominant group represents a way of normalizing the dominant group's status by making their privileges unremarkable (not worth speaking about). A lack of discourse for the marginalized group represents a way of normalizing the dominant group's status by rendering them silent, and by extension, rendering their experiences invisible. The existence of taboos around discussions of finances and open disclosures of class in the United States underscores why social class identities may be especially hard to measure in this context (Argyle, 1994; Sims, 1951).

What little class-based language does exist among Americans itself is heavily molded by discourse: class-based identity terms have a value-laden character, with the middle and upper but not working or lower classes being associated with "respectable citizens" (Hooper, 1976). This results in, perhaps, a more restricted discourse surrounding class. The negatively valenced nature of lower-income identity terms may make some economically disadvantaged individuals hesitant to identify with this marginalized group. They may be resistant to disclose their class identity for fear of being stereotyped. In either case, this represents another way in which the constructions of class in American society result in a heavy silencing of marginalized individuals, a group whose quietness ultimately contributes to the status quo reproducing invisible discourse of class.

\section{Social Class and Institutions of Higher Learning}

For the purposes of this project, we chose to focus on manifestations of class discourse and interruptions to class discourse as they develop within a higher educational context. Higher educational settings are a particularly fruitful place for this work because there is potential to examine both how dominant and challenging lines of class discourse occur and the effects these have on those coming to understand their own level of privilege or marginalization along lines of social class.

\section{Dominant Discourse}

Bourdieu suggests that the transmission of class-based values is linked to specific institutions which socialize members of a particular class to function in the roles that accompany their status. He further suggests that higher education is one such institution (Swartz, 1997). Qualitative studies of social class have explored how low-income students in college grapple with issues of "fit," and often must juggle more and varied demands than their middle-class counterparts (Bergerson, 2007; Kuriloff \& Reichert, 2003). Many low-income students begin to feel marginalized as the differences between them and better-off students become more and more obvious, which fosters the subjective consolidation of their childhood class identity (Bergerson, 2007; Jones, 2003; Stewart \& Ostrove, 1993). 
Using habitus as a guiding concept, we can begin to understand exactly how tangible markers of class are converted into cultural capital. One particular feature of habitus, its lack of explicitness and the way it minimizes discourse, has especially interesting implications for the study of class-based privilege. It suggests that the lived experience of class leads to certain values, expectations, and hopes - which are clearly distinct and not easily captured by objective markers of social class-but may not lead to subjective identification or class awareness.

\section{Intergroup Dialogues}

Intergroup dialogues are currently being implemented as teaching tools and interventions in a number of disciplines, including psychology, sociology, and social work (Dessel, Rogge \& Garlington, 2006). Intergroup dialogues are structured conversations between members of different social identity groups that have a history of conflict or tension which foster intergroup communication, exploration, and learning (Dessel, 2008; Dessel \& Rogge, 2008). These dialogues are facilitated by individuals knowledgeable about the conflict (often group members themselves) who have been trained to lead the discussions (Miller \& Donner, 2000).

Typically, intergroup dialogues are designed and structured to emphasize the importance and feasibility of social change with a specific emphasis on social justice and coalition building (Nagda, 2006). The goal of these dialogues is not simply to air grievances or allow both sides of a historically charged issue room to speak, but is instead to foster conflict reduction, commonality between participants, and collective commitment to social change (Dessel, 2010; Zuniga, Nagda $\&$ Sevig, 2002). The impact of cultural differences and historical power imbalances between groups is emphasized and explicitly discussed (Dessel, 2008). As such, intergroup dialogues can be considered sociopolitical in nature (Alimo, Kelly, \& Clark, 2002).

When considered in reference to Bourdieu's (1977) idea of habitus, intergroup dialogues represent the development of a social context which directly challenges and disrupts existing dominant discourse (Alimo, Kelly \& Clark, 2002). Within the context of these dialogues, which encourage individuals to engage in active listening to the perspective of other group members and a high level of critical self-reflection (Dessel, 2010), a safe environment is created where individuals are able to voice insights and ideas that may be taboo or inflammatory outside the dialogue. Given the emphasis on social justice, much of the guided conversation that takes place in the dialogues is focused on understanding and dismantling existing structural hierarchies. In essence, intergroup dialogues provide a space for individuals to examine and ultimately reject the unasked questions and assumptions that Bourdieu claims prop up structural inequalities. Participation in these dialogues, then, represents a form of social action itself (DeTurk, 2006). 
Intergroup dialogues have been implemented in academic, community, and international settings. This article will focus specifically on the outcomes seen with student-based dialogues, but research suggests that positive results have emerged in all three settings (Dessel, Rogge \& Garlington, 2006). Students participating in intergroup dialogues have been shown to end dialogue courses with increased perspective taking and greater awareness of the role of social identities in one's day-to-day life (Dessel, 2010; Dessel \& Rogge, 2008). Students in intergroup dialogue courses also develop a more sophisticated and nuanced understanding of structural inequalities, and are more likely to attribute inequalities to structural factors than personal factors (Dessel \& Rogge, 2008; De Turk, 2006; Lopez, Gurin \& Nagda, 1998). Finally, student participants of dialogues report generally positive feelings about their experience, cite the courses as helpful (Miller \& Donner, 2000), and leave with an increased commitment to progressive social action (Dessel \& Rogge, 2008).

\section{This Research}

This research investigates the relationship between an individual's class-based privilege and that individual's ability to engage in discourse about social class. We examined the types of discourse surrounding social class employed by economically advantaged and economically disadvantaged students in intergroup dialogue classes at a large Midwestern university. This particular research context was chosen because of its potential to disrupt dominant lines of class-based discourse in a setting where classed values are typically reproduced.

Qualitative data may be the best way to investigate may aspects of subjective class identity in large part due to the lack of discourse surrounding class. Social class identity may be hard to investigate through closed-ended self-report data specifically because (unlike with gender or race) there is not an accepted language to describe or label one's classed experiences, and often the language an individual uses is idiosyncratic and context-specific. Thematic content analysis was used to explore how awareness of class privilege is related to the level of discourse surrounding social class. Of particular interest were the ease or difficulty of discussing social class and the role dominant lines of discourse (or, alternatively, a lack of discourse) played in masking class privileges by those who enjoyed them. Given that little work in psychology has focused on how we discuss and understand social class, the research presented here is exploratory in nature.

\section{Method}

Archival analysis was conducted on a set of 102 final papers from participants who were enrolled in a semester long intergroup dialogue course which specifically focused on social class and class-based inequalities. The final paper 
required participants to reflect on what they had learned about social class in general and what they had discovered about their own social class identity throughout the course. To protect participants' anonymity, all demographic information was gathered as disclosed within the paper by the participant themselves: 44 participants self-identified as female, 28 self-identified as male, 31 participants did not disclose their gender; 47 participants self-identified as White, 55 self-identified as non-White; 37 participants self-identified as lower/working class, 56 participants self-identified as middle/upper class, 10 participants did not disclose their social class. These ten participants were dropped from the study, and were not used in any step of analysis.

Intergroup dialogue program as research context. Undergraduate students apply to join the intergroup dialogue program. Once enrolled, the student is assigned to one of that semester's ongoing intergroup dialogues. The student does not choose which dialogue section he or she participates in. The dialogues typically include sections on gender, race and ethnicity, socioeconomic class, and religion but have also included sections on sexual orientation, international students and U.S. students, and White racial identity as well.

The dialogue sections are courses worth two credit hours, usually crosslisted under psychology and sociology. The courses are structured to introduce dialogue as a particular technique for breaking through communication barriers in a meaningful and respectful way, with a focus on social justice. The sections are small (usually no more than 12-14 students) and have equal numbers of students from each relevant identity group (in the case of the socioeconomic dialogues, equal numbers of upper class and working class students). The course is led by two trained undergraduate facilitators, one from each identity group. These facilitators have previously participated in dialogues before and have undergone a rigorous training procedure with the program's staff. The participants in the dialogue are assigned readings, but much of the course is devoted to weekly two-hour long discussions in which all are expected to participate. At the end of the course, each student writes a 10-page paper reflecting on their experience throughout the semester.

Coding procedure. A coding scheme for this project was developed using the following multistep process. First, deductive content analysis was conducted on an initial set of 10 papers, which were read closely for themes by the authors. These initial 10 papers were excluded from any further analysis (between these papers and the papers by participants who did not disclose their class, we were left with a total of 82 papers to code). We discussed which themes to pursue and how to identify the presence of those themes in the text of subsequent papers. Based on comparisons of our notes, we developed a coding scheme for the difficulty in engaging in class discourse (Table 1). We also coded for reported level of salience of class at 
Table 1. Coding Scheme for Theme 1

\begin{tabular}{|c|c|c|c|}
\hline \multicolumn{4}{|c|}{ Coding } \\
\hline Subtheme & Theme content & Example codes & $\begin{array}{l}\text { Interrater } \\
\text { agreement }\end{array}$ \\
\hline $\begin{array}{l}\text { Class is } \\
\text { racialized }\end{array}$ & $\begin{array}{l}\text { Participant discusses } \\
\text { economic differences as } \\
\text { racial differences. }\end{array}$ & $\begin{array}{l}\text { "The results of the privilege walk } \\
\text { showed all of the minorities at the } \\
\text { back of the classroom and all of } \\
\text { the Whites at the front." }\end{array}$ & $98 \%$ \\
\hline $\begin{array}{l}\text { Discussing } \\
\text { class is taboo }\end{array}$ & $\begin{array}{l}\text { Participant discusses or } \\
\text { acknowledges societal } \\
\text { taboos about class-based } \\
\text { discourse. }\end{array}$ & $\begin{array}{l}\text { "I believe that in society, people are } \\
\text { taught that discussing money in } \\
\text { public is rude and that you are } \\
\text { never supposed to discuss your } \\
\text { income or the taxes you pay, with } \\
\text { the people outside of your } \\
\text { immediate family." }\end{array}$ & $92 \%$ \\
\hline $\begin{array}{l}\text { Class-based } \\
\text { stereotypes }\end{array}$ & $\begin{array}{l}\text { Participant discusses } \\
\text { valenced perceptions of } \\
\text { class groupings. }\end{array}$ & $\begin{array}{l}\text { "Poor people are seen to be lazy, and } \\
\text { to not value education." }\end{array}$ & $95 \%$ \\
\hline
\end{tabular}

Note. All themes listed above were coded for presence or absence in a given paper.

the beginning of the term. All participants reported an increased awareness and salience of their class identity at the conclusion of the term, but students started the term with different degrees of salience (Table 2). Second, the authors used this coding scheme to analyze all other papers written by participants who disclosed their socioeconomic status. Each paper was coded for the presence or absence of relevant themes. We compared our codings and revised the developing coding scheme.

When the coding scheme was sufficiently clarified and revised, two blind coders were trained independently to use it. They analyzed all the papers in isolation from the authors and from each other. Once all coding was complete, we compared the agreement of their codes with one another and with the first author. The coders were highly reliable (Tables 1 and 2 for agreement by theme). This established the reliability of the coding scheme used in our analysis. The analysis reported below is drawn from the first author's codes.

\section{Results}

The majority of participants (64 participants out of 82) reported feelings of self-discovery as a result of participation in the class-focused intergroup dialogues. These participants saw the class as a fulfilling experience which encouraged them to grow and learn more about their own identities. Feelings at the close of the 
Table 2. Coding Scheme for Theme 2: Salience of Class

\begin{tabular}{|c|c|c|c|}
\hline \multicolumn{4}{|c|}{ Coding scheme } \\
\hline Subtheme & Content & Example & $\begin{array}{l}\text { Interrater } \\
\text { agreement }\end{array}$ \\
\hline Self-discovery & $\begin{array}{l}\text { Presence-participant describes the } \\
\text { IGR dialogues as a fulfilling } \\
\text { personal experience. The } \\
\text { participant feels that the dialogues } \\
\text { have helped them form a greater } \\
\text { understanding of who they are as a } \\
\text { person. } \\
\text { Absence-participant did not discuss } \\
\text { IGR as a learning or growth } \\
\text { experience }\end{array}$ & $\begin{array}{l}\text { "This has been }[\mathrm{a}] \text { really } \\
\text { rewarding experience; I feel } \\
\text { like a new person." }\end{array}$ & $83 \%$ \\
\hline \multirow[t]{3}{*}{$\begin{array}{l}\text { Salience at } \\
\text { start of term }\end{array}$} & $\begin{array}{l}\text { Low-participant never considered } \\
\text { social class to be an important } \\
\text { aspect of their identity or } \\
\text { day-to-day life prior to the } \\
\text { dialogue }\end{array}$ & $\begin{array}{l}\text { "I have to admit that I never } \\
\text { realized how my } \\
\text { socioeconomic status } \\
\text { affected a lot of my } \\
\text { experiences: old and recent." }\end{array}$ & $92 \%$ \\
\hline & $\begin{array}{l}\text { High-participant had some } \\
\text { articulated understanding of their } \\
\text { social class which they saw as a } \\
\text { relevant facet of their identity prior } \\
\text { to the dialogue }\end{array}$ & $\begin{array}{l}\text { "It was easy for me to identify } \\
\text { myself as a member of the } \\
\text { lower-middle-class, because } \\
\text { it is one of my few identities } \\
\text { that has caused me some } \\
\text { hardship in my life. " }\end{array}$ & \\
\hline & $\begin{array}{l}\text { N/A - participant did not reference } \\
\text { their level of class salience prior to } \\
\text { the dialogue. }\end{array}$ & & \\
\hline
\end{tabular}

semester were highly positive; several participants cited the dialogue as the best class they had taken in their time in college, and several others professed an interest in taking additional dialogue courses in the future.

It is worth pointing out that these feelings of self-discovery are dependent on a low level of class salience at the start of the term. Salience at the start of term was coded for: participants were coded for low salience, high salience, or no mention. Only 12 participants came into the dialogue with high levels of class identity salience ( 7 from the upper/middle class group and 5 from the working class group).Three subthemes emerged to explain why social class was not a clear or visible or salient identity for most participants in the study at the start of the term.

Subtheme 1: Class is racialized. Class issues are embedded in racialized language, both by the students themselves and by the media at large. Often, class 
issues, such as low-income housing, lack of healthcare, or welfare, are more strongly associated with low-income minorities than low-income Whites. Although this is based in very real trends in society, often such issues are completely recoded as matters of race, which obscures their classed nature and the complicated relationship between class and race in American society.

I was always aware of differences in income and class, but I thought of them as something outside of the basic systems of oppression. I viewed systems of oppression primarily as race or gender, but race was always the primary system of oppression. (upper class, no other demographic information reported)

Within some of the dialogue courses, class and race became inextricably linked. Some participants wrote of how nearly all of the participants in the working class group were students of color, while the middle/upper class group was primarily made up of Whites. In such cases, the intersections of race and class led to differences in the degree to which participants conflated racial and classbased issues. Those with more than one marginal identity-non-Whites in the working class group, for example - teased apart and recognized the simultaneous impact of their race and class status more readily than White participants or upper/middle class non-White participants (for a more in-depth discussion of whiteness and intersectionality, see Case, 2012). Thus, in such cases, race-based privileges were discussed and engaged with by the dominant groups to a greater extent than class-based privileges, which further complicated the discourse about social class.

Subtheme 2: Taboos about discourse. A second aspect of this theme centered on the existence of taboos which prevent explicit discussion of social class or income. Participants described frank discussions of financial matters or concerns as "rude" or things one "is never supposed to discuss ... outside your immediate family" (both quotes from upper class participants, no other demographic information reported). Some participants, beyond just acknowledging that such a taboo exists, employed it in their papers. For example, one stated that "there is no need to point out" (upper class White woman) differences between the working class and middle/upper class groups, which effectively downplayed the impact of social class even within the dialogue itself.

Everyone in my group, including myself, kept stating that we never talked about money or our class growing up and so we never considered it and never connected certain things we were able to do with our wealth and socioeconomic status. (upper class White woman)

The taboo, in addition to being a mechanism one can use to minimize class differences, renders individuals mute on the issue of social class. Individuals lack the ability to cultivate a language or a discourse to effectively describe their own social class. This quote also suggests that when such labels are elusive, the topic itself may become decoupled from the experiential aspects of social class. 
Subtheme 3: Class-based stereotypes. The language which does exist to describe and discuss social class tends to be valenced and stereotypical. Participants were aware of negative stereotypes regarding low-income and poor people coming in to the dialogues. Members of the lower/working class group expressed hesitancy identifying themselves as low-income, poor, working class, etc., because of the implication that by doing so they "would not measure up to others" (working class non-White man) and that they "did not want anyone to feel sorry" (working class non-White woman) for them:

Many of the wealthy students in my dialogue never consciously tried to distinguish themselves as superior ... society said they were superior. (upper class Black woman)

This quote emphasizes the starkly valenced nature of the divide between low class individuals and everyone else, and emphasizes the pervasive nature of these beliefs.

Interestingly, upper/middle class students also sought to distance themselves from the other end of the continuum. These comparatively better-off students tried to emphasize that they were not wasteful, or thoughtless, or simply skating by on the basis of their more privileged position.

\footnotetext{
We've had to work just as hard, and even though we might have access to money and opportunities, we have all been taught the valuable lesson of hard work and therefore have to achieve success on our own. It is bothersome that we are stereotyped because of our wealth because everyone can have the same internal values and desires regardless of one's class. (upper class White woman)
}

Upper/middle class students are eager to dispel the idea that their privilege means that they are spoiled or slackers. They were quick to point out that they, like the working class group members, had to work hard to gain entrance to this prestigious university and continue to work hard to excel academically. However, these statements about the stereotypes of the wealthy are largely a defensive reaction against the difficulty associated with recognizing their own class privilege.

\section{Discussion}

Analysis of these final papers showed that participants came into the dialogues sections with generally low class salience at the start of term. After fourteen weeks of discussions and active learning about social class and economic privilege, participants still had difficulty articulating and discussing issues related to social class. A number of factors led to a lack of discourse about social class, even among participants involved in a semester-long dialogue course specifically focused on class issues. The lack of discourse was due, in part, to taboos preventing the explicit discussion of social class. Such taboos were especially pronounced among the upper/middle class participants. 
The legitimacy of privilege often relies on the naturalization of discriminatory practices or institutions (see Cole, Avery, Dodson, \& Goodman, 2012). Similarly, this lack of class-based discourse revealed interesting ways in which class privilege is maintained and seems to be "natural." Although there were obviously mechanisms in place to divert conversation away from class itself-either by reframing the conversation in terms of another identity, such as race, or through taboos against it - participants did seem to have an understanding of class privilege. The unearned advantages of their economic social position were clear enough to wealthy participants that they sought to qualify or distance themselves from their privileged position. This tactic, combined with the overall lack of discussion about class generally, acted both masked and normalized the existence of those unearned privileges.

The most intriguing quality of privilege is it seems so "natural." Bourdieu (1977; Swartz, 1997) argued that the lack of critical discourse around existing hierarchical structures naturalizes the habitus experienced by various class groups (i.e., the naturalization of the correspondence between the social position and personal disposition). The qualitative research presented here shows that taboos around the discussion of class exist in the United States, and that they serve to silence conversations about social class. Habitus, then, is a process of negotiating and understanding contextual economic elements in an implicit, nonverbalized way. The lack of discussion about these issues silences lower-income people and reproduces privilege for economically advantaged people. Interrupting this process by engaging in critical and explicit discourse about classed inequalities (such as occurred in the dialogues), however, can disrupt the process of habitus, which could lead to a different understanding of social class. Disruption of this process is important especially to upwardly mobile individuals, such as low-income and firstgeneration college students, who experience issues of fit within the predominately middle class institutions of higher education. Our findings suggest that until we are able to articulate and discuss the various aspects of our lived class based experiences, we cannot fully engage with our own levels of marginalization and privilege which are embedded in that habitus.

The importance of discourse should not be underestimated. The limits imposed by economic stratification lead to reduced opportunities for low-income individuals. The reduced opportunities and economic scarcity in turn shape the value systems and worldviews of those individuals. Classed opportunities, for example, can impact how an individual interacts with institutions such as schools, which can have important downstream effects on career aspirations and attained occupational prestige. Thus, discourse impacts how social class is subjectively construed, and how this level of subjective identification further entrenches objective economic situations. A lack of person-environment fit evident in economically disadvantaged students' attrition highlights these issues. Climate factors such as lack of fit may be closely related to the silencing and isolating effects of dominant class-based discourse. 
Also important to note is that a focus on habitus means that particular attention is paid to the importance of context, which shapes social class in multiple and sometimes unexpected ways. Investigation on the lack of discourse regarding social class experiences reveals how important an understanding of intersectionality and habitus are to the study of social class: in the American context, social class is a slippery and half-seen thing, an identity more felt than discussed, and one heavily shaded by the embodiment of other social identities. In the socioeconomic intergroup dialogues, we noted a tendency to conflate race and class issues. To some extent, this was a strategy used by the participants to reframe the content of the dialogues in ways that they felt comfortable discussing. It is important to note, however, how closely race and class are linked as identities. They are simultaneously present, often simultaneously salient, and mutually reinforcing. Future research can and should explore how other social identities-like gender, sexual orientation, ability status, and others-shape and are shaped by class (Coston \& Kimmel, 2012). Intergroup dialogues are an ideal context to study the mutual impact of multiple identities.

\section{Future Directions}

The research presented here was exploratory. Although these findings shed some light on how the lack of class-based discourse reproduces and shapes unearned class-based privileges, they open up many new avenues for future research. Future work could explore how attitudinal changes toward class and social justice occur throughout the dialogue process. Employing a longitudinal design which analyzes journal entries, comments made during the course, etc., would shed light on where participants' views on class started and how they shifted over the course. Such a design would further allow researchers to explore the strategies used by participants to understand the nature of class privileges they may hold themselves.

A major limitation of this work is that all of the research presented here was conducted in the United States, and is likely unique in important ways to the American context. Americans have historically had a different kind of relationship to social class than other cultures. Although social class is a visible and salient aspect of identity for many other cultures, in the United States the impact and relevance of social class is masked. There are several reasons why the discourse of class in America is limited. The American context is one marked by a history of explicit, structurally enforced racism, which has resulted in a strong link between wealth accruement and racial privilege. Discussions of class occur, but often are reframed as discussions of race.

Further complicating this is that this research was conducted in an exclusively American context with American citizens. Immigrant populations likely have a very different relationship to and understanding of social class. Immigration status may intersect with social class in very interesting and complex ways-for example, 
the class status of an immigrant performing menial labor is very different than that of an immigrant recruited for a high-level position. Each of these hypothetical immigrants may have similar educational backgrounds and credentials - suggesting that they may hold relatively consonant class status in their place of origin - but may for a variety of structural reasons face very different opportunities in the United States. There is a distinct possibility, then, that immigrants hold multiple, sometimes conflicting and always context dependent class identities. As global economies become more tightly entwined, the need to take a transnational perspective and incorporate the experiences of immigrants only becomes more important to the study of identity and class.

\section{Conclusions}

The research presented here suggests that an understanding of the fluency and implicitness of discourse surrounding social class sheds light on how and why economically advantaged individuals are unable to articulate the privileges associated with their positions. When said discourse is largely absent, economically advantaged individuals have a difficult time understanding and critically evaluating their privileges. Economically disadvantaged individuals, on the other hand, tend to be more aware of the impact social class on their lived experiences and opportunities, but are also constrained by a lack of explicit class discourse. The dominant invisible discourse of class silences them, effectively removing their experiences from the dominant group's line of sight. We found that these barriers to a challenging and system-changing class discourse are hard to overcome; participants struggled to articulate their feelings about class even after an intensive semester-long class-focused dialogue course.

\section{References}

Alimo, C., Kelly, R., \& Clark, C. (2002). Intergroup dialogue program student outcomes and implications for campus radical change: A case study. Multicultural Education, 10, 49-53.

Argyle, M. (1994). The psychology of social class. New York: Routledge.

Bergerson, A. A. (2007). Exploring the impact of social class on adjustment to college: Anna's story. International Journal of Qualitative Studies in Education, 20, 99-119. doi: 10.1080/0951839060923610.

Bourdieu, P. (1977). Outline of a theory of practice. Cambridge, UK: Cambridge University Press.

Bullock, H. E., \& Limbert, W. M. (2003). Scaling the socioeconomic ladder: Low-income women's perceptions of class status and opportunity. Journal of Social Issues, 59, 693-709. doi: 10.1046/j.0022-4537.2003.00085.x.

Case, K. A. (2012). Discovering the privilege of Whiteness: White women's reflections on antiracist identity and ally behavior. Journal of Social Issues, 68, 78-96. doi: 10.1111/j.15404560.2011.01737.x.

Cole, E. R. (2009). Intersectionality and research in psychology. American Psychologist, 64, 120-180. doi: $10.1037 / \mathrm{a} 0014564$. 
Cole, E. R., Avery, L. R., Dodson, C., \& Goodman, K. (2012). Against nature: How arguments about the naturalness of marriage privilege heterosexuality. Journal of Social Issues, 68, 46-62. doi: 10.1111/j.1540-4560.2011.01735.x.

Coston, B. M., \& Kimmel, M. (2012). Seeing privilege where it isn't: Marginalized masculinities and the intersectionality of privilege. Journal of Social Issues, 68, 97-111. doi: 10.1111/j.15404560.2011.01738.x.

Dessel, A. (2008). Intergroup dialogue. In A. Gitterman \& R. Salman (Eds.), Encyclopedia of social work with groups (pp. 80-83). Binghamton, NY: Routledge.

Dessel, A. B. (2010). Effects of intergroup dialogue: Public school teachers and sexual orientation prejudice. Small Group Research, 41, 556-597. doi: 10.1177/1046496410369560.

Dessel, A., \& Rogge, M. (2008). Evaluation of intergroup dialogue: A review of the empirical literature. Conflict Resolution Quarterly, 26, 199-238. doi: 10.1002/crq.230.

Dessel, A., Rogge, M. E., \& Garlington, S. B., (2006). Using intergroup dialogue to promote social justice and change. Social Work, 51, 303-315.

DeTurk, S. (2006). The power of dialogue: Consequences of intergroup dialogue and their implications for agency and alliance building. Communication Quarterly, 54, 33-51. doi: 10.1080/01463370500270355.

Gordon, M. (1951). A system of social class analysis. Drew University Bulletin, 39, 3-19.

Hooper, M. (1976). The structure and measurement of social identity. The Public Opinion Quarterly, 40, 154-164. doi: 10.1086/268284.

Jones, S. J. (2003). Embodying working-class subjectivity and narrating self: "We were the hired help". In D.L. Tolman \& M. Brydon-Miller (Eds.), From subjects to subjectivities: A handbook of interpretive and participatory methods (pp. 145-162). NY: NYU Press.

Kamieniecki, S., \& O’Brien, R. (1984). Are social class measures interchangeable? Political Behavior, 6, 41-59. doi: 10.1007/BF00988228.

Kuriloff, P., \& Reichert, M. C. (2003). Boys of class, boys of color: Negotiating the academic and social geography of an elite independent school. Journal of Social Issues, 59, 751-769. doi: 10.1046/j.0022-4537.2003.00088.x.

Lopez, G. E., Gurin, P., \& Nagda, B. A. (1998). Education and understanding structural causes for group inequalities. Political Psychology, 19, 305-329. doi: 10.1111/0162-895X. 00106.

Mahalingam, R., \& Leu, J. (2005). Culture, essentialism, immigration and representations of gender. Theory \& Psychology, 15, 841-862. doi: 10.1177/0959354305059335.

Marx, K., \& Engels, F. (1962). Manifesto of the Communist Party, section I ("Bourgeois and proletarians"). In Selected works [of] Karl Marx and Frederick Engels (Vol. 2, pp. 33-43). Moscow: Foreign Languages Publishing House.

Miller, J., \& Donner, S. (2000). More than just talk: The use of racial dialogues to combat racism. Social Work With Groups, 23, 31-53.

Nagda, B. A. (2006). Breaking barriers, crossing borders, building bridges: Communication processes in intergroup dialogues. Journal of Social Issues, 62, 553-576. doi: 10.1111/j.15404560.2006.00473.x

Pinterits, E. J., Poteat, V. P., \& Spanierman, L. B. (2009). The white privilege attitudes scale: Development and initial validation. Journal of Counseling Psychology, 56, 417-429. doi: $10.1037 / \mathrm{a} 0016274$.

Schooler, C., \& Schoenbach, C. (1994). Social class, occupational status, occupational selfdefinition, and job income: A cross-national examination. Sociological Forum, 9, 431-458. doi: 10.1007/BF01466317.

Sims, V. (1951). A technique for measuring social class identification. Educational and Psychological Measurement, 11, 541-548. doi: 10.1177/00131644510110401.

Stewart, A. J., \& Ostrove, J. M. (1993). Social class, social change, and gender: Working-class women at Radcliffe and after. Psychology of Women Quarterly, 17, 475-497. doi: 10.1111/j.14716402.7993.tb00657.x.

Surridge, P. (2007). Class belonging: A quantitative exploration of identity and consciousness. The British Journal of Sociology, 58, 207-226. doi: 10.1111/j.1468-4446.2007.00148.x.

Swartz, D. (1997). Culture and power: The sociology of Pierre Bourdieu. Chicago: The University of Chicago Press. 
Zuniga, X., Nagda, B. A., \& Sevig, T. D. (2002). Intergroup dialogues: An educational model for cultivating engagement across differences. Equity and Excellence in Education, 35, 7-17. doi: $10.1080 / 713845248$.

MELISSA SANDERS is a doctoral student in psychology at the University of Michigan. Her research interests include the development of social class-based identity, how social power is perceived and understood, and how individuals develop an awareness and understanding of their own intersecting identities.

RAM MAHALINGAM is an Associate Professor in Psychology at the University of Michigan. In one line of research he investigates how extreme female discrimination affects community mental health in various parts of India. In another line of research, he has been studying the impact of model minority stereotypes on the psychological well-being of Asian Americans. He is also investigating the professional identity development of women engineers in India. He also examines whether nurturing mindful awareness enhance the resilience of members of marginalized community members. He edited two books: Multicultural Curriculum (Routledge) with Cameron McCarthy; Cultural Psychology of Immigrants (Lawrence Erlbaum). 